\title{
Learner Involvement in Language Development: From Course Design to Performance Assessment
}

\author{
Abdulmoneim Mahmoud \\ Department of English, College of Arts \& Social Sciences, Sultan Qaboos University, Muscat 123, Sultanate of Oman
}

\begin{abstract}
The mismatch between teaching and learning is believed to be one of the factors that militate against the effectiveness of instruction. Such a contention has led language teaching specialists to call for a learnercentered approach to bridge the gap between teaching and learning. In this approach, the students are expected to shoulder the responsibility of their own learning through participation at all levels of the teachinglearning process, from planning the program to assessment of performance. This article provides some ideas and practical classroom techniques and procedures that can foster learner involvement at all stages of language teaching from course design to performance assessment. These techniques and procedures are presented direct involvement (learner-centered) and indirect involvement (learning-centered). The former include course evaluation, essay writing and error correction; the latter include form-focused instruction: giving linguistic explanations in teaching grammar and error correction.
\end{abstract}

Index Terms - learner involvement in language development

\section{INTRODUCTION}

Our language teaching approaches, methods and techniques become more effective as we know more about the learners and their needs and their learning strategies, styles and preferences. The teaching methods and classroom techniques should be informed by knowledge about the learning process. Effective teaching methods and techniques can, in turn, result in effective learning. Thus, the processes feed into each other. Over three decades ago, researchers (e.g. Naiman, Frolich and Todesco, 1978) stressed that language teaching methods are rendered ineffective by not involving the learners, directly or indirectly, in the teaching-learning process.

The essence of the learner-centered approach to language teaching and learning is to let the students take the responsibility of their own learning and to allow them to have the choice of what to learn and how and when to learn it, (see e.g. Ali, 2000; Baeten et al, 2010; Blumberg, 2008; Liu et al, 2006; Sarigoz, 2008; Schuh, 2004; Thanasoulas, 2000). Such an approach is also referred to as 'student-centered' and 'child-centered'. Learner-centeredness entails having the learners participate and play a central role in classroom activities under the teacher's guidance. As Mahmoud (forthcoming) says, "certain aspects of planning and teaching are beyond the discretion of the teacher, especially in formal classroom language learning situations." For instance, in the Arab countries where English is taught as a foreign language (EFL), decisions related to language planning and language policy - which foreign language(s) should be taught, which variety of the language should be taught and at which educational level - are made by the ministries of education in general education and by the colleges and universities in higher education institutions. In such situations where most, if not all, of the teaching-learning elements are pre-arranged, the teachers are left only with the classroom techniques and activities at their disposal. In his classroom-oriented action study, Mahmoud (ibid) shows how learnercenteredness can be achieved in teaching translation and in checking reading comprehension. In teaching translation, students can be involved at all stages of the process through group and whole-class discussion of each other's translations. First they translate the text individually then discuss their translations in pairs or small groups to produce one version to be discussed by the whole class under the teacher's guidance. Here are the steps:

Step1: Students read the passage and find the meanings of the new words and expressions individually or in pairs and groups.

Step 2: Students translate the text individually then in small groups and produce one final version to be presented to the whole class for discussion.

Step 3: The whole class discuss each group's translation one at a time under the teacher's guidance.

In checking comprehension, students are asked to translate an English text into Arabic (the first language). The teacher translates the incorrectly translated parts back into English and uses the back-translations to develop True/False questions and multiple-choice distracters. The following are the steps:

Step 1: Students read the passage and translate it into their first language as a comprehension check.

Step 2: The teacher lists the incorrectly translated parts and translates them back into the foreign language.

Step 3: The back-translated words and sentences are used to develop True/False and multiple-choice questions.

Thus, Mahmoud talks about two types of learner-involvement: direct involvement where students translate and discuss their translations in small groups and as a whole class (i.e. learner-centered) and indirect involvement where the back-translations of the students' incorrect translated words and sentences are used to develop objective reading 
comprehension questions. He refers to this latter type of involvement as 'learning-centered' because it is based on the students' learning and communication strategy of reliance on previous linguistic knowledge.

The purpose of this article is to take Mahmoud's (ibid) study a step further by discussing how learner-centeredness can be achieved at all stages of the language teaching process from course design to performance assessment through direct (learner-centered) and indirect (learning-centered) involvement of the students. More specifically, this paper shows how the students can be directly involved in course panning through course evaluation and at all stages of essay writing from the choice of topics to error correction. It also shows the students can be indirectly involved in formfocused instruction. The techniques and procedures described in this study are based on more than ten years of actual classroom teaching (2000-2012) at sultan Qaboos University, Oman, where EFL is taught to students majoring in three separate strands: Education, Literature and Translation. These students study post-intermediate and advanced courses in EFL skills (reading, writing, listening, speaking and grammar) in the first two years (four semesters). They are divided into groups of 15-20 male and female students and taught each skill as a separate course, (two two-hour sessions per week). The students usually spend a foundation year at the language center where they study intermediate level EFL courses. Assertions about the effectiveness of techniques presented in this article are based on the positive evaluations ( $80 \%-100 \%$ favorable) that the courses consistently obtain at the end of each semester. The course evaluation tool is an online questionnaire designed by the University. It includes an objective section consisting of 16 multiple-choice items and a subjective section composed of three open-ended questions, (see Appendix).

\section{DiRECT InVOLVEMENT}

\section{Course Evaluation}

According to Nunan (1995, p. 136), the first step towards learner-centeredness is to make the students aware of the objectives, content and materials of the course. In higher education institutions, this is usually done by giving the students a detailed outline of each course. As Nunan (1995, p. 144) says, "In some foreign language contexts, the notion of student choice may be relatively unfamiliar or even alien. In such a case, it is preferable to engage the learners in a relatively modest level of decision making." In some institutions, students are directly involved in decision making with regard to course design and teaching techniques through course and teaching evaluation conducted at the end of each semester. In some universities and high institutes, an evaluation tool is developed and used to solicit students' feedback on the content of each course and all aspects of teaching including assessment. The survey may consist of objective questions or open-ended ones or both. The most important step in the evaluation is how the data are utilized, if at all, after they are analyzed and returned to the course instructors. In fact, some teachers do not even care to look at these evaluations either because they believe that the students are not in a position to undertake such a task or because they believe that a negative evaluation will not jeopardize their survival in the institution. This indifference on the part of the instructors has detrimental consequences. Without such feedback from the learners, it might be difficult for the teacher to get to know what is effective and, therefore, can be retained and what needs to be abandoned or modified. If batches of learners systematically point out some drawbacks in the teaching or assessment techniques or in the teaching materials, adherence to these techniques and materials defeats the purpose of the practice. The students do not take the course evaluation seriously if their suggestions and comments are not taken into account. They either ignore it completely or do it as an abominable chore without even reading the items of the questionnaire. Thus, the students are denied the opportunity to participate in decision making regarding the content and materials of the course and the teaching and assessment procedures. Incorporation of the students' ideas and suggestions may guarantee their involvement in the teaching-learning process and help the teachers in their endeavor to attain perfection.

\section{Essay Writing}

This section discusses two learner-centered activities in a writing course for the second-year university English majors. In this course, students are required to write 700-1000-word argumentative essays. The course builds on previous courses covering paragraph writing using various writing modes (i.e. narration, description, analysis, comparison \& contrast, definition, etc.). The first two or three weeks (4-6 two-hour sessions) are devoted to preparatory work on:

(1) choosing an argumentative topic.

(2) writing a good thesis statement with a clear topic and controlling idea.

(3) the basic concepts and principles of argumentation.

Meanwhile, each student is asked to prepare a list of at least five argumentative topics of their own choice. The instructor then merges the same or similar topics and compiles a list of the most common topics. The second step is to present these topics for class debate. In a two-hour session, the instructor introduces the topic that the students want to discuss most and asks them to form teams based on their opinion about the issue, (i.e. with, against, undecided). The remaining class time (about 90-100 minutes) is spent on preparation and presentation of arguments by each team. The teams also refute opposing views. This debate helps students:

(1) apply the rules and principles of argumentation.

(2) argue with actual, rather than hypothetical, opposing side.

(3) consider and refute counter-arguments which they would not otherwise anticipate.

(4) write the essay with a real audience in mind, rather than writing to the teacher. 
The students are given the opportunity to organize and moderate the debate by themselves if they want. One or two students take charge each time. They introduce the topic, divide the class into groups, distribute participation turns, oversee proper application of the rules and principles of argumentation and make concluding remarks. The debate helps in brain-storming, critical thinking and in practicing speaking, note-taking and conversation skills. The essay is then written as a homework assignment. Thus, all of the preparatory stages of writing (choice of topic, brain-storming, audience, etc.) are learner-centered whether the students participate individually or in group. The writing stage is, of course, learner-centered since it is free writing where the student chooses:

(1) the major and minor supporting points.

(2) the opposing views that need to be refuted.

(3) the writing modes to be used to develop the essay.

For the purpose of the final examination, the students also write a number of reading-based essays where they read and respond to argumentative articles. Here again, the whole process is learner-centered. After reading the text, which is an individual activity, the students work together in groups and employ social strategies (asking questions and cooperating with each other) in order to:

(1) find the meanings of the words and expressions that they do not know.

(2) find the main points used to support the thesis and examine them critically.

(3) see how the writer refutes the opposing views and examine the refutations critically.

(4) debate the issue and add any other supporting or opposing views not in the article.

As in speaking-based writing, students write the essay as a homework assignment where they respond to the article showing their position based on the debate.

\section{Error Correction}

Related to writing is the issue of provision of feedback. Feedback is any response to the learner's use comprehension or production - of the target language whether that response is positive or negative, verbal or written, direct or indirect. Like grammar instruction, it is believed to enhance accuracy and accelerate the learning process, (see also James, 1998). Feedback is given also because students expect it and ask for it (Chandler, 2004). With regard to the provision of negative or corrective feedback (i.e. error correction), "learner-centeredness entails giving the students the opportunity to correct their own errors”. (Mahmoud, 2011, p. 10). Ellis (2009, p. 7) agrees with Lyster (2004) and Ferris (2006) when he says "there is evidence to suggest that prodding the learner to self-correct is effective in promoting acquisition." Most of the direct techniques used in correcting students' written work can be described as learnercentered since the learners have to figure out the correct forms by themselves. Such techniques include:

(1) mere indication of the location of the deviation by, for instance, underling it.

(2) using correction codes or symbols to show the type of the deviation.

(3) giving linguistic explanations that can help the student arrive at the correct form.

However, mere indication of the location of the incorrect part may not be helpful since it does not show the type of the deviation; the student may not know what is wrong with the underlined part, (Is it grammar, vocabulary, spelling, etc.?). Using correction codes can solve this problem; it is also more economical than giving linguistic explanations, especially in large classes, (see Mahmoud, 2000). Indirect techniques such as exposure to the language through listening and reading and recasting the incorrect part are considered learner-centered in the sense that the task of noticing the correct form is left to the learner. Providing the correct form directly is, by definition, teacher-centered; it deprives the learner of the opportunity to self-correct or even to notice the correct form as in indirect correction. Learnercenteredness can be realized by having the students correct themselves individually, in pairs, or in group and by giving the opportunity to choose the technique of correction they prefer. From personal experience and from informal discussions with some university writing instructors, students prefer correction codes most probably because of their cognitive maturity and relatively high level of proficiency in the language. We also observed that students prefer to work individually at first and then get together to discuss and correct the remaining errors in pairs and groups; they refer to the instructor for verification. In cooperative work, a student learns not only from his errors but from those of his classmates, (for other benefits of self-correction see e.g. Mahmoud, 2000).

\section{INDIRECT INVOLVEMENT}

\section{Grammar Instruction}

The teaching of grammar is as old as language teaching and it is still believed to be an important component of language pedagogy, (see e.g. Erlam et al, 2009; Nassaji et al, 2004). The role of grammar in language development is supported theoretically (see e.g. Ellis, 1987; James, 1986) and empirically (see e.g. Harley, 1989; Scott, 1990). In foreign language teaching contexts, grammar instruction can be a short cut to the learning of forms and structures. Accorind to Widdowson (1990, p. 162), "the whole point of language pedagogy is that it is a way of short circuiting the slow process of natural discovery." Grammar instruction can accelerate the process by supporting the learner's natural rule-discovery procedure, that is, it can aid the hypothesis formation and verification process. It adds to, confirms or modifies the tentative rules that the learners discover by themselves, (see also Mahmoud, 1997). Acknowledging the role grammar instruction in language learning, the focus of debate has shifted to the issue of the kind of grammar to be taught and how best it can be taught. It is generally agreed that the kind of grammar to be taught is the one that is 
simplified and presented in a way that it can easily be digested by the learners (i.e. pedagogical grammar). However, an important difference between many pedagogical grammars and the learners' rule-discovery procedure is that the former contain relatively elaborate analyses and metalinguistic terms observed in reference grammars. The learners' rulediscovery process does not operate on the basis of such metalanguage and analysis. As Ellis (1990, p. 186) says, "it is important to recognize that explicit knowledge does not require metalingual expertise." In the same vein, McLaughlin (1987, p. 30) states, "People have rules of language use in their heads but these rules are not those of the grammarian." James (1998, p. 264) also agrees that pedagogical grammars are not accessible to the learners because "they are too closely related to the linguists' grammars they are derived from." Reduction of analysis while retaining the metalanguage may result in pedagogical grammar but not learners' grammar. One main objection to the use of metalinguistic terms in grammar instruction is that they have nothing to do with the way whereby people actually process language as we see in the above quotations from Ellis (ibid) and McLaughlin (ibid). The ultimate goal of language teaching is to enable students to 'learn' the language, not to describe it. Information about how language is learned appears to be more important to the teacher and the learner than telling them about the details of how language works. Thus, one way of achieving learning-centeredness in grammar instruction is to approximate the learner's natural hypothesis formation process by reducing the analysis and metalanguage to the absolute minimum. From personal experience, a teacher may not need more than eight basic terms: verb, adverb, noun, pronoun, adjective, preposition, subject and object. In situations where the learners have a common native language learned in a formal classroom context (e.g. modern standard Arabic), existence of one-to-one equivalents of these terms will be an advantage.

Provision of Negative Feedback

From the types of errors that language learners commit, it is clear that the hypothesis formation process draws upon previous linguistic knowledge. Learners rely on their first language and what they know from the target language (i.e. their interlanguage) as a compensatory strategy. Here comes in the strategy of association and reliance what is known to learn the unknown. Interlingual and intralingual association (i.e. linguistic transfer) is a psycho-cognitive strategy employed to fill in the gaps in the target language knowledge and facilitate both learning and communication. Based on this strategy, grammar and vocabulary instruction can be learning-centered through simplified contrastive comparisons. Approximation of the learner's hypothesis formation process can be realized not only by reducing metalanguage and analysis but also by comparing and contrasting grammatical forms and structure and lexical items interlingually and intralingually. For instance, when explaining the use of the English definite article, cognitively mature students who share the same first language might benefit from a brief comparison between their L1 and English. Such an interlingual comparison can make the students aware of cases of possible positive and negative transfer, something which they naturally - consciously or subconsciously - do in their attempt to learn or use another language.

The teachers who choose to give linguistic explanations as a technique of providing corrective feedback might also employ such simple and brief interlingual and intralingual contrastive comparisons. For instance, addition of the definite article 'the' to the abstract noun 'life' is a common error made by Arab learners of English even at the university level. The error is most probably due to reliance on Arabic as a source of hypothesis formation (i.e. interlingual transfer). Hence, a brief comparison between English and Arabic might be effective. In case of ambiguous errors those which could be attributed to both L1 and L2 - the teacher needs to make interlingual as well as intralingual comparisons since the same error could be committed by two or more students for different reasons, (see also Mahmoud, 2011). It could also be made by one and the same student for different reasons at different stages in his language development. To make grammar instruction and error correction learning-centered and learner-centering at the same time, the students can be directly involved in making such comparisons with the teacher's guidance. In other words, the students can verbalize their hypothesis formation process and get their associations verified. When teaching vocabulary, a target lexical item can be compared with a synonym, an antonym, a derivative, a synform, or L1 equivalent, (for more information and examples see Mahmoud, 2011).

\section{CONCLUSION}

Based on practical classroom EFL teaching experience, this article shows how learner-centeredness can be achieved in course design, free writing and form-focused instruction. Such an approach is believed to bridge the gap between teaching techniques and learning strategies. Students can be directly involved in course design through end-of-semester course evaluation. This procedure helps the teacher to address the learners' needs and preferences. The article also presents classroom techniques and procedures that can involve the students directly through group and whole-class participation (i.e. learner-centered) and indirectly through strategy-based teaching (i.e. learning-centered). Students can be directly involved at all stages of process-oriented free writing from the selection of the topic and brain storming through debates and in error correction through the use of correction symbols. Students can also be indirectly involved in the teaching-learning process when grammar instruction and provision of corrective feedback is based on their learning and communication strategies. Linguistic explanations in grammar and vocabulary instruction and in error correction can approximate the natural hypothesis formation process where the students rely on previous linguistic knowledge to facilitate the task of learning and using another language. Since the assertions of the effectiveness of the learner-centered and learning-centered techniques described in this paper are based on students' evaluations of the 
courses, further systematic studies are needed to verify the effectiveness of these techniques compared to the traditional teacher-centered techniques.

\section{REFERENCES}

[1] Ali, S. (2000). Learner-centered vocabulary building in practice. The Internet TESL Journal, 6 (12), Retrieved 15 July 2012 fron http://iteslj.org/Techniques/Ali-vocabulary.html

[2] Baeten, M., Kyndt, E., Struyven, K. and Dochy, F. (2010). Using student-centered learning environment to stimulate deep approaches to leaning. Educational Research Review, doi: 10.1016/j.edurev.2010.06.001.

[3] Blumberg, P. (2008). Developing Learner-Centered Teachers: A Practical Guide for Faculty. San Francisco: Jossey-Bass.

[4] Chandler, J. (2004). A response to Truscott. Journal of Second Language Writing, 13, 343-348.

[5] Ellis, R. (1987). Does instruction work? In J. Coleman and R. Towell (Eds.), The Advanced Language Learner. London: SUFLRA/CILT.

[6] Ellis, R. (1990). Instructed Language Acquisition. Oxford: Oxford University Press.

[7] Ellis, R. (2009). Corrective feedback and teacher development. Second Language Journal, 1, 3-18.

[8] Erlam, R., Philp, J. and Edler, C. (2009). Exploring the explicit knowledge of TESOL teacher trainees. In R. Ellis et al. (Eds.), Implicit and Explicit Knowledge in Second Language Learning, Testing and Teaching. Bristol: Multilingual Matters.

[9] Ferris, D. (2006). Does error feedback help student writers? In K. Hyland and F. Hyland (Eds.), Perspectives on Response. Cambridge: Cambridge University Press.

[10] Harley, B. (1989). Functional grammar in French immersion. Applied Linguistics, 10, 331-359.

[11] Hayward, F. (1905). The Education Ideas of Pestalozzi and Foebal. London: Ralph Holland.

[12] James, C. (1986). Five uses of grammar in foreign language teaching. Anglo-American Studies, 6, 101-115.

[13] James, C. (1998). Errors in Language Learning and Use. London: Longman.

[14] Liu, R., Qiao, X. and Liu, Y. (2006). A paradigm shift of learner-centered teaching style. Arizona Working papers in SLAT, 13, 77-91.

[15] Lyster, R. (2004). Differential effects of prompts and recasts in form-focused instruction. Studies in Second Language Acquisition, 26, 399-432.

[16] Mahmoud, A. (1997). Learner-centered grammar instruction. English Teaching Forum, 35, 50-51.

[17] Mahmoud, A. (2000). Coded corrective feedback: In search of a compromise. TESL Reporter, 33, 10-17.

[18] Mahmoud, A. (2006). Translation in foreign language reading comprehension: A neglected didactic procedure. English Teaching Forum, 44, 28-33.

[19] Mahmoud, A. (2011) The role of interlingual and intralingual transfer in learner-centered EFL vocabulary instruction. Arab World English Journal, 2, 28-49.

[20] Mahmoud, A. (forthcoming). Some learner-centered techniques in FL teaching, Academic Exchange Quarterly.

[21] McLaughlin, B. (1987). Theories of Second Language Learning. London: Edward Arnold.

[22] Naiman, N., Frolich, N. and Todesco, A. (1978) The good language learner. RESL Talk, 5, 55-58.

[23] Nassaji, H. and Fotos, S. (2004). Currect developments in research on the teaching of grammar. Annual Review of Applied Linguistics, 24, 126-145.

[24] Sarigoz, I. (2008). Towards individual centered foreign language teaching. Journal of Language and Linguistic Studies, 4, 5164.

[25] Schuh, K. (2004). Learner-centered principles in teacher-centered practices? Teaching and Teacher Education, 20, 833-846.

[26] Scott, V. (1990). Explicit and implicit grammar teaching strategies. French Review, 63, 779-789.

[27] Thanasoulas, D. (2000). What is learner autonomy and how can it be fostered? The Internet TESL Journal, 6 (11), Retrieved April 142012 from http://iteslj.org/Articles/Thanasoulas-Autonomy.html.

[28] Widdowson, H. (1990). Aspects of Language Teaching. Oxford: Oxford University Press.

Abdulmoneim Mahmoud has an associate professor with a BEd, MA and PhD degree in applied linguistics. He teaches courses in applied linguistics, contrastive linguistics, language acquisition and English-Arabic-English translation. He is interested in classroom-oriented research in TEFL, an area where he published articles in local regional and international journals. 